\title{
A propósito de un análisis desde las relaciones públicas: la revisión yuxtaposicional de la comunicación y la persuasión, una encrucijada para confrontar la industria farmacéutica*
}

\author{
Diana Carolina Spell ${ }^{* *}$ \\ Mónica Gallego Ruiz ${ }^{* * *}$ \\ Juan Carlos Molleda**** \\ Lauren Bayliss ${ }^{* * * * *}$ \\ Mauricio Álvarez Moreno****** \\ Luis Horacio Botero Montoya ${ }^{* * * * * * *}$ \\ Recibido: Enero 15 - Aprobado: Marzo 15
}

\section{Resumen}

Este artículo pretende indagar la manera como las corporaciones farmacéuticas multinacionales en Canadá, Colombia, Perú y los Estados Unidos establecen sus relaciones con sus públicos internos y externos y, específicamente, ahondará en las estrategias y tácticas

\footnotetext{
Este artículo proviene de resultados preliminares de la investigación Estrategias de comunicación y relaciones públicas orientadas a la construcción de persuasión, confianza y reputación, por los organismos gremiales, entes reguladores y genéricos de marca del sector farmacéutico, con presencia en Canadá, Estados Unidos, Colombia y Perú. Proyecto cofinanciado por las universidades San Martín de Porres (Perú), Florida (Estados Unidos), y Medellín (Colombia).

* Magíster en Relaciones Públicas. Responsable del programa de pregrado en Relaciones Públicas de la Facultad de Ciencias de la Comunicación de la Universidad de San Martín de Porres en Lima- Perú. Dirección electrónica: spellcarolina@hotmail.com

... Candidata a magíster en Comunicación. Docente de Relaciones Públicas de la Universidad de Medellín y miembro del grupo de investigación en Relaciones Públicas y Comunicación-Greco- de la Universidad de Medellín. Dirección electrónica: monica.gallego@medellin.gov.co

...* Doctorado en Comunicación Masiva mención Relaciones Públicas Internacionales y Negocios Internacionales. Profesor y jefe encargado del Departamento de Relaciones Públicas y director del Postgrado en Comunicación Estratégica Global de la Facultad de Periodismo y Comunicaciones de la Universidad de Florida en los Estados Unidos. Dirección electrónica: jmolleda@ufl.edu

....* Estudiante de Doctorado, Facultad de Periodismo y Comunicaciones de la Universidad de Florida, donde es instructora de Principios y Estrategias de Relaciones Públicas. Dirección electrónica: lbayliss@ufl.edu

....** Magíster en Comunicación Educativa, máster en Relaciones Internacionales. Profesor de tiempo completo de la Facultad de Comunicación de la Universidad de Medellín. Coordinador del Centro de Investigación en Comunicación. Miembro del Grupo de investigación COP (Comunicación Organización y Política). Dirección electrónica: maualvarez@udem.edu.co

........ Doctor en Relaciones Internacionales Iberoamericanas. Jefe de la División de Relaciones Internacionales de la Universidad de Medellín. Dirección electrónica: Ihbotero@udem.edu.co
} 


\title{
About an Analysis from Public Relations: A Joint Review of Communication and Persuasion; A Crossroad for Confronting Pharmaceutical Industry.
}

\begin{abstract}
This article is intended to enquire about the way how multinational pharmaceutical corporations in Canada, Colombia, Peru, and the United States establish their relations with internal and external publics, but the article will specifically go deep into the strategies and methods used for promoting preference for generic drugs and their potential benefits.

The study this article is based on is grounded on a multidimensional line of work which incorporates communication theories and public relations, focused on aspects such as persuasion and trust as quality indicators in relationships; the study also includes aspects of the conceptual framework that we have addressed in a research entitled "Communication Strategies and Public Relations Focused on the Construction of Persuasion, Trust, and Reputation by Unions, Regulating Entities, and Brand Generics of the Pharmaceutical Sector with Presence in Canada, the United States, Colombia, and Peru;" besides, it is an important evidence of the theoretical and argumentative support shown by such study in its reference framework.
\end{abstract}

Key words: Communication; strategies; public relations; persuasion.

usadas, para promover la preferencia por los medicamentos genéricos y sus beneficios potenciales.

El estudio que da origen al artículo está basado en una línea de trabajo multidimensional que incorpora teorías de comunicación y relaciones públicas, centradas en aspectos como la persuasión y la confianza como indicadores de calidad en las relaciones; agrupa aspectos del marco conceptual que hemos abordado en la investigación titulada: "Estrategias de comunicación y relaciones públicas orientadas a la construcción de persuasión, confianza y reputación por los organismos gremiales, entes reguladores y genéricos de marca del sector farmacéutico, con presencia en Canadá, Estados Unidos, Colombia y Perú" y, además, es una muestra importante del soporte teórico y argumentativo que presenta dicho estudio en su marco referencial.

Para investigar las estrategias y tácticas usadas para la segmentación de públicos, el estudio usa el modelo de procesos de problemas (Hallagan, 2001), y para los asuntos propios de la promoción del valor social de las compañías farmacéuticas multinacionales se retoma la conceptualización del economista Gabriel Tarde (citado por Latour, E Lépinay, 2009; Wärneryd, 2007). Finalmente, el tema de la confianza será considerada un moderador vital de las habilidades de las compañías estudiadas a la hora de desarrollar accesibles y positivas actitudes y un nivel alto de valor social que redunde en bienestar de las farmacéuticas y sus productos.

Palabras clave: comunicación, estrategias, relaciones públicas, persuasión 


\section{Introducción}

Si bien la investigación sobre Estrategias de comunicación y relaciones públicas orientadas a la construcción de persuasión, confianza y reputación por los organismos gremiales, entes reguladores y genéricos de marca del sector farmacéutico, con presencia en Canadá, Estados Unidos, Colombia y Perú se centra en la industria farmacéutica, especialmente, aquella que fabrica medicamentos genéricos de marca, lo que desarrolla este artículo puede aplicarse a cualquier organización, dado el alcance global que tienen los aspectos teóricos expresados.

Este trabajo, que sometemos a la comunidad académica, se constituye en el soporte teórico que sustenta la investigación y representa un avance en el camino de la misma. El trabajo está basado fundamentalmente en cuatro partes que son los fundamentos centrales de la investigación: la comunicación estratégica, las relaciones públicas, la persuasión y la teoría de las emociones, abordadas desde una mirada multidimensional y desde múltiples autores y teorías.

Para (Searle,1997: 37) la comunicación es un proceso que conecta lo que el hablante quiere decir, lo que este emite, su intención y aquello que el oyente comprende, sumado al cumplimiento de las reglas que gobiernan la interacción, haciendo, por tanto, que se construyan o destruyan las percepciones; es por ello que analizar las estrategias de comunicación y, sobre todo, aquellas aplicadas por las empresas de la industria farmacéutica para persuadir a sus públicos de interés, puede ser de especial interés para la sociedad, si tomamos en cuenta que el carácter de su negocio está vinculado a la salud.

La imagen de una organización es determinante en la elección de las actividades, los servicios o los productos que ofrece. Lo que el público piensa u opina de una empresa o institución es producto de la información que la organización decide emitir hacia el interior o exterior. Por lo tanto, es necesario comunicar lo que se pretenda en ella, mediante información entregada de manera lógica, clara e institucional, es decir, por medio de un plan estratégico de comunicación concreto. En general, para que cualquier tipo de empresa o institución se comunique con su público específico, en cualquier situación, ya sea al ingresar a un nuevo mercado o en un momento de crisis, es necesaria la elaboración de un plan estratégico de comunicación, que involucre los asuntos propios de la persuasión y la teoría de las emociones, para que ayude a alcanzar los objetivos establecidos previamente.

Si concebimos que comunicar es persuadir y persuadir es buscar efectos, entonces, la comunicación se convierte en una herramienta más de gestión, orientada a la obtención de los objetivos estratégicos de la empresa. Cabe preguntarse ¿Por qué es necesaria la gestión de la comunicación en la empresa? En el contenido del artículo tratará de darse respuesta a este cuestionamiento.

\section{Metodología}

La construcción de la metodología del proyecto de investigación ha sido de carácter participativo, en el que docentes investigadores junto con sus estudiantes auxiliares han fomentado el diálogo para la elaboración de la misma. 
El primer paso fue identificar los principales laboratorios farmacéuticos que están establecidos en el país, productores de medicamentos genéricos; gremios (Asinfar, Afidro, Cecif) y entidades del Gobierno (MinSalud, Invima) que guardan relación con la industria abordada. Posteriormente, se procedió a hacer un rastreo web en los principales medios de comunicación y páginas oficiales, con un rango de fecha entre los años 2011 y 2013. El total de fichas recolectadas para Colombia en cuanto a asociaciones farmacéuticas y entidades del Gobierno fue de 42 distribuidas de la siguiente manera: Asinfar: 13, Afidro: 9, INVIMA: 9, Minsalud: 8, CECIF: 5. Después de la última revisión de la ficha, los coinvestigadores de los otros países miembros de la investigación sugirieron una instrucción para cada variable; con base en dicha instrucción se completó el análisis de cada una de las noticias y artículos recopilados.

A través de una jornada de socialización y análisis, se realizó una lluvia de ideas donde se determinaron los conceptos primordiales para la creación de la ficha, principal insumo de la investigación.

La herramienta de análisis se dividió en tres categorías: persuasión, reputación y confianza; dentro de estas variables se delimitó el análisis con conceptos como inoculación (intención), lenguaje (actitud), poder (racionalidad), imaginarios (imagen, percepción) ética (prestigio), técnica (eficiencia), responsabilidad social corporativa, liderazgo. Luego de elaborada la ficha, se envió a los países partícipes de la investigación para su revisión y ajuste. Una vez recibidas las correcciones se procedió a dar lectura rigurosa a cada una de las noticias recopiladas en cuanto a asociaciones y entidades del Gobierno, aplicando el instrumento de manera crítica.

\section{Comunicación estratégica}

En la actualidad, cuando las organizaciones, la tecnología y los discursos crecen a pasos agigantados la comunicación y los esfuerzos de fortalecimiento de la imagen corporativa se constituyen en las estrategias que permiten garantizar el éxito, ya que es un trabajo que va más allá de la publicidad y del marketing; la comunicación estratégica es fundamental en la dirección de una organización y sirve a los objetivos del marketing. Scheinson (2009) plantea que

[...] la comunicación debe exceder los límites de los productos y las marcas para, además, ser articulada de manera inteligente en una gestión global y con la aplicación de una lógica eminentemente estratégica para llevarla a cabo desde la única área que lo hace posible, esto es, la del top management.

Según lo anterior, es posible dividir las comunicaciones en dos ámbitos: el primero de ellos considera las herramientas como las relaciones públicas, promoción, diseño, publicidad, entre otras; el segundo asume la comunicación estratégica como aquella que corresponde a la gestión y el aprovechamiento del sistema en el que se articulan dichas herramientas. Dicho de otra manera, la comunicación estratégica enmarca actividades como delinear, administrar y controlar la política y estrategia comunicacional, a partir de la sensibilidad, la inteligencia, la paciencia, la constancia y la firmeza, entendiendo la 
comunicación como la razón de ser de toda organización. En consecuencia, no se trata solo es promocionar y publicitar sus productos sino darse a conocer a sí misma, mostrar cómo desarrolla sus productos, cómo logra sus objetivos y quiénes conforman los equipos de trabajo, es decir, destacar aquello que la hace única y singular.

Lo anterior no solo mejora los procesos tanto internos como externos, sino que humaniza a la organización ante los consumidores: "El consumidor compra y elige con base en una evaluación que él elabora, en forma consciente y/o inconsciente. Estas ventajas que actúan como parámetros de elección, se denominan 'ventajas diferenciales'” (Scheinsoh, 2009). De tal manera, es posible hablar de la integración de los conceptos de publicidad de productos y publicidad institucional, para conjugar relevancia y significancia en una misma campaña, dado que el público quiere conocer a fondo las organizaciones y los procesos que le entregan un producto final. Además, es un deber de la empresa comunicar para generar tranquilidad en sus clientes y, a su vez, influenciar de forma positiva en la opinión pública, pues toda ausencia de comunicación puede convertirse en comunicación negativa, como lo expresa Daniel Scheinsohn en su libro Comunicación estratégica!

Por consiguiente, es indispensable que las organizaciones aprovechen sus diferentes procesos para comunicar de manera acertada y asertiva, debido a que todas sus actuaciones repercuten de alguna manera en los públicos. De manera que, omitir no es una forma óptima de evitar impactos negativos; todo lo que compete a las organizaciones tiene mensajes implícitos que el consumidor está analizando, y el hecho de que una organización no utilice medios de comunicación no quiere decir que los consumidores no estén construyendo una imagen de ella. Todos los comportamientos de las organizaciones comunican la imagen; en tanto registro y lectura pública de la empresa, ella no ha de ser entendida netamente como un efecto visual, ya que compromete la totalidad de los comportamientos de la empresa.

La comunicación estratégica impulsa el concepto de personalidad corporativa; no solo se trabaja desde la imagen y la identidad, sino a partir de las características que hacen única a la organización dentro de su entorno, ya que al igual que en los humanos, las organizaciones cuentan con aspectos motivacionales: misión, supuestos, metas y actitudes corporativas. Todo lo anterior le permite concentrar sus recursos y esfuerzos determinando las iniciativas y actuaciones para garantizar su crecimiento y calidad.

De igual manera, es posible afirmar que la comunicación estratégica busca convertir la opinión individual y/o colectiva en una representación positiva de la imagen corporativa, mediante la integración de los diferentes procesos comunicativos operacionales, para favorecer la reputación de las organizaciones.

1 A fines de la década de 1980, a partir de la publicación de la primera edición del libro: Comunicación estratégica se resaltó la importancia de comprender esta idea para diferenciarla de la comunicación táctica (táctica en el sentido de técnicas como: publicidad, relaciones públicas, promoción, diseño, etc.) que en el contexto de una gestión estratégica de la comunicación, cumplen la función de enmarcar y contener a las tareas de índole primordialmente operacional. 
En síntesis, la comunicación estratégica es el engranaje de tres conceptos fundamentales: personalidad corporativa, que está estrechamente relacionada con la identidad y los rasgos esenciales que diferencian las organizaciones; la imagen, que corresponde a los significados que asocian los públicos a las organizaciones y, finalmente, la reputación, que corresponde al juicio ante la comparación de la organización en cuanto a su excelencia.

\section{La comunicación y lo estratégico}

Las organizaciones, asumidas como empresas o instituciones, son cada una un "corpus", un organismo, como lo explica Joan Costa²:

La idea de 'corporación' es sinónima de organización y significa, en español, agrupación, comunidad o asociación" (...) "ha ido adquiriendo una lógica global —la organización como un todo, un corpus - y un sentido funcional que yo llamaría 'gestalista' porque es una constatación fundamental de que el 'todo es más que la suma de las partes' —ya que implica importantes sinergias entre ellas, las sumas por el contrario, no son sinérgicas" (Costa, 1995).

Para Costa, el sentido de corporativo se construye en la unidad de la organización, en una mirada que podríamos denominar holística. El mismo autor, al relacionar el "corpus" o lo "corporativo" con el desarrollo de las organizaciones afirma que de este modo, el concepto corporatista puede ser interpretado como un paradigma de la gestión organizacional global o, más que global, integral. De este modo nacen concepciones como «comunicación corporativa" o "comunicación y relaciones corporativas" y la propia "comunicación estratégica". Incluso, y al decir del propio Costa, la comunicación es estratégica cuando es corporativa, es decir, integral, holística (Costa, 1995).

Ahora bien, conferirle a la comunicación un carácter estratégico tiene múltiples implicaciones teóricas y prácticas. Esto es así dado que, si bien se ha planteado — desde los discursos ideales - que la comunicación es el lugar de una "común unión" ${ }^{3}$, hay que reconocer que su ámbito es potencialmente el conflicto, dado que los sujetos que entran en relación comportan: intenciones, propósitos y pasiones que aunque no siempre explícitos, en cualquier caso determinan sus formas de relación y transacción. Es aquí donde cobra sentido lo afirmado por teóricos del discurso como Teun Van Dijk, Searle, White o Field, (1992) cuando señalan que todo enunciado se produce para alterar la posición del otro, bien sea: informándolo, convenciéndolo o persuadiéndolo. Lo anterior permite apostar por una comprensión de la comunicación como relación contractual que se instaura entre sujetos empíricos que al instalarse en el lenguaje construyen los sujetos del discurso. De esta manera, mientras los primeros están inscritos en unas prácticas sociales que de múltiples formas los determinan -universo del hacer- los sujetos discursivos lo están en el universo del decir.

2 Al respecto, Joan Costa ha trabajado desde esta perspectiva en varios textos y, principalmente, en el texto titulado: "Comunicación Corporativa y la revolución de los servicios", publicado en Madrid. 1995.

3 Comunicación proviene del latín comunicare que epistemológicamente significaban dos cosas: 1) Poner en común y 2) Comulgar, hacer la comunión con algo. 


\section{Las relaciones públicas}

Como una de las tantas herramientas que manejan las organizaciones hoy, las relaciones públicas son en la actualidad la más importante estrategia de comunicación de mediano y largo plazo, para lograr opiniones favorables de los distintos públicos con los que una empresa interactúa.

Las relaciones públicas surgieron como una necesidad de la sociedad en los tiempos modernos. Su ejercicio nació rudimentariamente en la Antigüedad, pero, como veremos al estudiar más a fondo su desarrollo, es a principios de nuestro siglo cuando recién podemos hablar de una verdadera disciplina, avanzando con fuerza sobre el mundo de los negocios y el gobierno. El avance de la influencia de la opinión pública en las decisiones que toman no solo los entes gubernamentales, sino las empresas con fines lucrativos, las entidades deportivas, culturales, educacionales, artísticas y de cualquier otra especialidad, hace que la existencia de las Relaciones Públicas sea imprescindible para manejar con fluidez la comunicación con los grupos de interés de las organizaciones.

Las relaciones públicas no son un proceso estático, sino que requieren de continuidad y dinamismo; tienen un sentido de permanencia, ya que cuando empiezan a darse, quienes las aplican deben ser conscientes de que no pueden detenerlas, ya que esto alteraría la imagen y el prestigio alcanzados, a través de ellas, cortaría el proceso que se inició en la organización y se perdería la credibilidad que se ha logrado frente a los públicos.

Para conocer y profundizar en el tema es necesario hablar de la aparición de las relaciones públicas en el mundo. Comenzamos citando a Roggero (1970), quien dice que: "Atribuir una fecha exacta al nacimiento de las relaciones públicas es muy difícil". El autor señala que el inicio de estas se dio en el mismo momento en que tomaron vida las relaciones sociales, y tuvo origen en los grupos organizados en el mundo laboral. Por su parte, Xifra (2010) afirma que la historia de las relaciones públicas es la historia de los Estados Unidos, y viceversa, y agrega que, a pesar de esta americanización de la historia de la disciplina, su práctica es casi tan antigua como la misma comunicación humana.

Así las cosas, puede decirse que la ideología y la filosofía de las relaciones públicas están estrechamente ligadas a los principios morales en los que se sustenta la democracia. Esta comparación reside en que al igual que el concepto de democracia se funda en la libertad y la justicia para un mayor número de personas las relaciones públicas se basan en el deseo del ciudadano-consumidor, y de esta manera el interés público debe encontrar la satisfacción óptima en un determinado patrón de comportamiento por parte de todo tipo de organismos.

Por otro lado, para autores como Black (1991) la utilización del término tiene sus orígenes en 1807, al ser usado por el presidente de los Estados Unidos, Tomas Jefferson, quien sustituyó el concepto de "estado de pensamiento" por el de "Relaciones Públicas". No obstante, como señala Black al hacer una revisión más profunda partiendo desde los anales de la antigua Grecia y del Imperio Romano, se descubre que estas se centran en la importancia del cuidado de la opinión pública por parte del Gobierno. 
Ahora bien, Arceo (1988) sostiene que: "Desde que el ser humano habita el mundo, han existido de una u otra forma, acciones para hacerse notar personalmente o encaminadas al servicio de su país o comunidad, de una idea política, religiosa, filosófica etc." Retomando la idea expuesta por Black (1991) y Xifra (2010) se puede afirmar que los Estados Unidos son la "cuna de las Relaciones Públicas", ya que fue allí donde se sentaron las bases que permitieron pasar del empirismo puramente aplicado a la teorización racional de la disciplina.

Por su parte A. Castillo (2010) define las relaciones públicas como una disciplina que cuenta con una presencia esencial en el seno de las organizaciones, dado que coadyuvan a la gestión estratégica de la comunicación de las mismas. El autor señala, además, que la expresión anglosajona "Public Relations" no ha sido traducida de manera correcta, ya que según este autor debería haber sido expresada como relaciones con los públicos. También sostiene que la esencia de las relaciones públicas consiste en conocer, gestionar e investigar a los diferentes públicos que posee una organización.

De acuerdo con esto, al considerar esta traducción se podrían evitar connotaciones tergiversadas sobre su función y alcance, dado que toda organización ya sea empresa, movimiento asociativo, sindicato, partido político, organización no gubernamental o asociaciones patronales debe conocer con quiénes se relaciona, establecer acciones con ellos, conocer sus demandas y satisfacer sus necesidades de una manera acorde con los objetivos de la organización, de la misma manera que las entidades públicas (poderes Ejecutivo, Legislativo y Judicial) deben relacionarse con sus públicos, para establecer vínculos satisfactorios mutuamente.

Así, la historia de las relaciones públicas da cuenta de cómo su teorización se iba realizando a medida que la propia sociedad demandaba actuaciones más cualificadas y una aportación más rigurosa y contrastable. Frente a un inicio en el que los precursores de las relaciones públicas actuaban sin ninguna fundamentación teórica y se basaban primordialmente en la intuición y el instinto, la disciplina fue migrando su campo discursivo y cobrando mayor relevancia en la medida en que se generalizaba su uso en los ámbitos privado y público.

Hace dos décadas, una definición comúnmente aceptada de las relaciones públicas era: "Hacer el bien e informar a la gente de ello". Scott, Cutlip, Allen y Center, en su obra Effective Public Relations, dicen "que las Relaciones Públicas: son el esfuerzo planeado para influenciar la opinión mediante el buen carácter y la ejecución responsable, basados en una comunicación de dos direcciones mutuamente satisfactorias". La definición anterior concibe el proceso como "un esfuerzo planeado que utiliza la comunicación en dos direcciones para provocar el resultado final de influenciar a la opinión" (Cutlip, Scott. y otros, 2000).

De otro lado, en las tres definiciones del término, presentadas por la tercera edición del Webster's New International Dictionary, (3. ${ }^{a}$ edición, 1982: 60) se describen las relaciones públicas, así: 
a. La promoción de simpatía y buena voluntad entre una persona, empresa institución y otras personas, público especial o la comunidad en su conjunto, mediante la distribución de material interpretativo, el desarrollo del intercambio amistoso y la evaluación de la reacción pública.

b. El grado de comprensión y buena voluntad logrado entre un individuo, organización o institución y el público.

c. El arte o la ciencia de desarrollar la comprensión y la buena voluntad recíproca, el personal profesional a cargo de esta tarea.

A través del recorrido por las diferentes definiciones dadas a las relaciones públicas, puede verse que no existe un acuerdo generalizado entre los autores a la hora de presentar el tema. Es así como en la Asamblea Mundial de Asociaciones de Relaciones Públicas, celebrada en Ciudad de México en 1978, se hizo la siguiente declaración: "La práctica de las Relaciones Públicas, es el arte y la ciencia social de analizar tendencias, predecir sus consecuencias, aconsejar a los líderes de las organizaciones y llevar a cabo programas planificados de acción que servirán al interés del público y las organizaciones".

Contrastando las definiciones de las relaciones públicas, nos encontramos con una de las primeras que fue la desarrollada por el Public Relations News, el primer boletín de noticias semanal. John Marston, autor de Modern Public Relations, agrega dos palabras a esa definición, que puede verse en la siguiente declaración: "Las relaciones públicas constituyen la función administrativa que evalúa las actitudes del público, identifica las políticas y los procedimientos de una organización con el interés público, y ejecuta un programa de acción y comunicación para ganar la comprensión y la aceptación del público" (Marston, 1963).

Avanzando en la revisión de una definición que se acerque el quehacer de la disciplina, nos encontramos con la más reciente, propuesta por la Sociedad de Relaciones Públicas de América (PRSA) a mediados del 2012, y que fuera el fruto de una campaña para buscar una definición más dinámica y que se adecuara a las necesidades de la época actual: "Las relaciones públicas consisten en el proceso estratégico de comunicación que construye relaciones mutuamente beneficiosas entre las organizaciones y sus públicos".

A partir de lo anteriormente expuesto, se evidencia que realizar una revisión de la teoría de las relaciones públicas implica reconocer los aportes de los investigadores en la materia, y para ello se hace necesario revisar en la historia de sus orígenes y su evolución si se quiere entenderlas en un contexto global. En este sentido, se puede encontrar que muchos teóricos coinciden en afirmar que el estudio de los fundamentos de las relaciones públicas cobra gran utilidad para obtener una perspectiva interior de sus funciones y técnicas. Los esfuerzos orientados a dominar la fuerza de la opinión y la comunicación con los demás se remontan a la Antigüedad más lejana, y lo único relativamente nuevo hoy son los instrumentos, el grado de especialización y la intensidad del esfuerzo requerido.

Una definición ampliamente utilizada, tomada de la cátedra de la Universidad Argentina John F. Kennedy (2001) y que sigue siendo válida en nuestros días introduce el concepto 
de público y lo define como un término colectivo para designar a un conjunto de personas estrechamente relacionadas entre sí por los intereses y afinidades que les son comunes y que comparten un sentimiento de solidaridad con la organización.

Tomando en cuenta las diferentes posturas, autores y corrientes citadas, resulta evidente que las relaciones públicas componen una actividad profesional propia de las organizaciones, definida como un sistema multidisciplinar estrechamente ligado a la alta dirección y que, apoyado en el conocimiento científico, investiga a los públicos con los cuales se relaciona, con el objetivo de planificar, elaborar y ejecutar estrategias de comunicación para lograr la integración y el consenso.

De tal modo que el fin de las relaciones públicas se manifiesta en el deseo por impedir y solucionar los conflictos que se presentan entre una organización y sus públicos, salvaguardando en todo momento la cohesión (Aguadero, 1993). Podríamos agregar que: "La legitimidad última de las relaciones públicas está en satisfacer el derecho a la información del público" (Soria, 1997), pues solo así podrá lograr la integración que pretende, fortaleciendo el "bien común" y la confianza de la opinión pública.

No hay duda de que la misión de las relaciones públicas radica esencialmente en la formación del consenso a corto o a mediano plazo. Solano Fleta (1999) sostiene que la finalidad de esta disciplina responde a dos objetivos principales: "La realización y mantenimiento de la cohesión social, mediante la actuación de aquellos procesos de comunicación intragrupales e intergrupales susceptibles de generar y mantener un alto grado de solidaridad entre los sujetos que los realizan".

La satisfacción de los públicos demanda de las organizaciones no solo el apoyo gerencial a la labor del relacionista, sino también el fomento de un espíritu cooperativo y solidario. Este contexto favorable debe armonizarse con objetivos importantes, tales como el asesoramiento a la dirección, y la permanente investigación y análisis de ambientes en los que actúa la organización. En este sentido, y tal como lo afirma Xifra (2007) "las relaciones públicas pueden percibirse ampliamente como la gestión de la comunicación, para establecer relaciones recíprocas mutuamente beneficiosas". Sería menester, por tanto, estudiar qué hacen los profesionales de las relaciones públicas en las organizaciones, y para las organizaciones o sujetos promotores.

Por tanto, el objetivo de las relaciones públicas no es fabricar imágenes ideales de las empresas y los empresarios para venderlos a la opinión pública. Ante esa simplificación teórica, creemos que esta práctica multidisciplinaria resuelve los conflictos emergentes entre las instituciones y los públicos. La promoción de la integración, en todos los niveles de la sociedad, ayudaría a alcanzar la productividad y la excelencia (en el entorno de la empresa), alentando el progreso y el bienestar en la nación.

Todo lo anterior, es decir, el recorrido histórico realizado por las relaciones públicas es fundamental para el presente estudio porque permite conocer el proceso de estas en el mundo, sus cambios y avances, y vincularlos como posibles factores que aporten al desarrollo de los planteamientos de la presente investigación. 


\section{La persuasión}

Persuadir ${ }^{4}$ consiste en mover a otras personas a aceptar nuestro punto de vista de manera voluntaria. Es un intento deliberadamente ejercido por parte de una persona o grupo para cambiar las actitudes de otras personas. Los estudiosos del tema afirman que la persuasión es una actividad o proceso, por medio del cual se intenta inducir un cambio en las creencias, actitudes o comportamientos de otra persona o grupo de personas, transmitiendo un mensaje en un contexto en el que el persuadido posee determinado grado de libertad de elección.

En la actualidad, debido al aumento de la competencia entre empresas por atraer al consumidor y/o cliente, las disciplinas de comunicación, como las relaciones públicas, toman cada vez más fuerza, sobre todo por ser más efectivas y directas, y -como su nombre lo dice- por influenciar en los públicos a los cuales las organizaciones quieren dirigirse para posicionarse y ser más rentables. Por tanto, es importante determinar las técnicas de comunicación que deberán estar enfocadas a esos públicos para mantener viva la credibilidad y confianza en los mensajes que da a conocer una empresa. Para poder llegar a los públicos es necesario persuadirlos mediante estrategias planificadas, aunque en ocasiones las dificultades se encuentren en la coincidencia del interés público con relación a lo que la organización busca. Por esta razón, la persuasión es uno de los elementos estratégicos más importantes a tener en cuenta.

\section{Persuasión y argumentación}

Hablar de persuasión y argumentación resulta un proceso dispendioso, máxime teniendo en cuenta que existen múltiples miradas y posturas desde diferentes áreas o campos del saber. Estas posturas van desde la filosofía y la psicología, y sus variantes (como el psicoanálisis y/o el conductismo), hasta posturas desde la sociología con su teoría de la sociedad de masas o la antropología y hasta la misma comunicación. En las siguientes líneas, trataremos de plasmar algunos referentes teóricos que nos permiten nutrir un marco de referencia para los propósitos de la investigación, no sin antes aclarar que se trata de una especie de collage sobre diferentes posturas y tendencias.

De acuerdo con María del Mar García Gordillo, investigadora de la Universidad de Sevilla, en su texto: Asignaturas en red. Periodismo político internacional (2008), la argumentación, en términos generales y específicamente en textos de carácter periodístico, requiere de pruebas lógicas para convencer, y psicológicas para emocionar. En este caso, agrega García Gordillo, se trataría de una argumentación con fines persuasivos, pero es preciso señalar que en ocasiones las pruebas no son lógicas, sino en la apariencia y que el fin de la argumentación no es manifiesto, por lo que se convierte en manipulación.

4 A partir de su teoría de los actos de habla, John L. Austin estableció desde que la persuasión es un acto perlocucionario, es decir, uno de los efectos producido por un hablante sobre otro por medio de un discurso. Aristóteles ya había definido la retórica como la facultad de considerar en cada caso lo que cabe para persuadir, es decir, que para Aristóteles la persuasión se produce, ciertamente, por el discurso, y si esto es así, ellas deben poder expresarse mediante el lenguaje discursivo. Dado lo anterior, es claro que además de que el hombre se comunica también se expresa mediante el lenguaje discursivo 
La argumentación, según Luisa Santamaría, puede definirse de la siguiente forma: "acto por el cual una persona, o un grupo, intenta conducir a un auditorio a adoptar una posición recurriendo a las exposiciones o aserciones dirigidas a demostrar la validez o la fundamentación" (Santamaría, 1990).

Perelman, otro autor que habla de la argumentación, señala que la elección misma de dichas premisas y su formulación, con las adaptaciones que entraña, solo rara vez están exentas de valor argumentativo: "se trata de una preparación o un razonamiento que, más que una disposición de elementos, constituye un primer paso para su empleo persuasivo" (Perelman, 1989). Estas premisas, que son la base de la argumentación, están compuestas por hechos, presunciones, valores -abstractos y concretos-, jerarquías y lugares - de la cantidad, de la cualidad, del orden-.

El objetivo final de toda argumentación, dice Perelman, no es otro que provocar o acrecentar la adhesión a las tesis presentadas para su asentimiento: "una argumentación eficaz es la que consigue aumentar esta intensidad de adhesión de manera que desencadene en los oyentes la acción prevista (acción positiva o abstención), o, al menos, que cree, en ellos, una predisposición, que se manifestará en el momento oportuno" (Perelman, 1989).

Por otro lado, Berrío (1983) afirma que la herramienta de trabajo de la argumentación es el entimema, entendido como el razonamiento deductivo de la retórica y se corresponde con el silogismo en el campo de la dialéctica. Se diferencian en que el entimema no pretende demostrar sino tan solo argumentar. En definitiva, lo que busca es la persuasión.

Las premisas utilizadas en la argumentación representan una parte esencial de la misma. "Así, sea cual sea la naturaleza del juicio es preciso encontrar unos lugares comunes al orador y a su audiencia que servirán de premisas para las argumentaciones" (Berrío, 1983).

Para Berrío (1983), la persuasión, o como él mismo denomina, las argumentaciones de carácter persuasivo introducen en los dominios de lo que se denomina razón contingente; unos dominios en los que no hallamos verdad ni mentira absolutas, sino relativas; en pocas palabras: nos hallamos de lleno en los dominios de la verosimilitud. Por tanto, continúa el autor, en la persuasión tenemos, primero, una práctica argumentativa destinada a actuar en la interacción comunicativa de los individuos en la sociedad y, segundo, una racionalidad basada en la lógica de la contingencia. Por tanto, y según Berrío, el acto persuasivo se caracteriza por

a. Tener como punto de partida una competencia comunicativa similar o claramente diferente. En este último caso se partirá de unos niveles de conocimientos diferentes entre emisor y receptor, sobre el tema objeto de persuasión.

b. Su intencionalidad, que nos definirá la finalidad del acto, será evidente y no escondida y, por lo tanto, única en unos casos y doble en otros, intencionalidad que el emisor intentará que sea compartida con el receptor.

c. Un uso emotivo del lenguaje abundante; un uso retórico del lenguaje con una estrategia adecuada, la cual administrará las razones probantes. 
d. La naturaleza de las afirmaciones y de los razonamientos utilizados basados en la verosimilitud como criterio de verdad.

Además, Berrío dice que es importante anotar que el persuasor tendrá una competencia superior en lo que respecta al tema objeto de la persuasión que aquel al que se intenta persuadir; esto le permitirá la organización de la estrategia del discurso. La intención del persuasor, por tanto, se manifestará a través de la citada estrategia en un discurso o en un conjunto de discursos. Lo que se buscará, por tanto, será el cumplimiento del objetivo del acto comunicativo, utilizando los elementos que sean precisos, entre los que sobresaldrán las razones probantes.

Apelando a la filosofía y al discurso aristotélico, Borrat (1989) señala la importancia que tienen las pruebas aristotélicas para establecer una relación entre emisor y receptor. Estas pruebas son tres: a) El logos, es la prueba lógica. Cualidad convincente de la evidencia y los argumentos. b) El ethos, es la prueba ética. Credibilidad e integridad del orador. Y, c) El pathos, es la prueba emocional. Condición emocional de la audiencia. Del mismo modo el autor señala que:

Las diversas combinaciones que se pueden establecer entre estas pruebas aristotélicas pueden servir para marcar distinciones en el discurso político del periódico. Así, el periódico elitista privilegia el logos y el periódico popular privilegia el pathos. Los editoriales privilegian el logos y las columnas el pathos. El ethos, sin embargo, parece, según Borrat, el requisito sine qua non de todo periódico (Borrat, 1989).

\section{Persuasión y manipulación}

Robert Escarpit (1983) ubica el origen del término manipulación en el ejército romano, donde la compañía llevaba el nombre de "manípulo" (literalmente, lo que cabe en el hueco de la mano). De acuerdo con el mismo autor:

La dimensión manipular correspondía a una situación en que el jefe aún tenía vías de comunicación directas e inmediatas con sus subordinados, como la voz y el gesto, lo que le permitía manipular a su unidad globalmente, insertándose él mismo en la red informativa interna que le otorgaba su identidad. Pero aunque este fuera su origen, ciertamente el término ha adquirido nuevas dimensiones (Escarpit, 1983).

Ahora bien, para Raúl Rivadeneira,

[...] la manipulación es, según el punto de vista de los periodistas, el manejo de los materiales noticiosos; para el publicista, el propagandista y el agente de Relaciones Públicas, es la técnica de atrapar la atención y el favor del público hacia un fin específicamente predeterminado; para los psicólogos, es control de las motivaciones (Rivadeneira, 1984).

Todos estos puntos de vista tienen importancia en la consideración del fenómeno de opinión pública, pues todo cuanto recibe el público por los diferentes medios ha pasado previamente por mecanismos de producción donde los materiales han sido adecuados y manejados por varios subsistemas. 
Entre tanto, y acudiendo al uso de la palabra, Berrío señala que

[...] la manipulación es un uso del lenguaje destinado, como la persuasión, a la influencia de la conducta humana, pero que se diferencia de ella por un conjunto de razones éticas, psicológicas y también, posiblemente, por unas características específicas del mismo proceso de persuasión, entendido este en toda su complejidad (Berrío, 1983).

De acuerdo con Berrío las diferencias entre persuasión y manipulación pueden establecerse en dos puntos:

En primer lugar, las premisas que se utilizan en la manipulación suelen ser falsas. Estas pueden ser presentadas como verosímiles e incluso como ciertas, pero el orador conoce su naturaleza y la esconde. En este caso, el argumento puede ser falaz. El orador parte de la conclusión que quiere imponer y busca las premisas oportunas, aunque estas no convengan realmente a la conclusión. En segundo lugar, se establece una diferencia en el aspecto ético; aquí el emisor se mueve en el terreno de la ambigüedad o de la mentira porque se persiguen unos objetivos éticamente condenables. Siguiendo a Berrío se puede señalar que la manipulación se caracteriza porque:

a. Se parte del supuesto de la competencia comunicativa del sujeto de la manipulación, pero desconocerá los aspectos fundamentales del proceso, por lo que diremos que es menos competente en esta cuestión concreta.

b. Existirán dos niveles de intencionalidad, una escondida pero que será la real y la que dominará el proceso, y otra operante, constituida por el discurso y que se querrá transmitir.

c. La existencia de dos niveles de lenguaje como en todo uso retórico y al igual que ocurre en la persuasión.

d. La naturaleza de las razones y de los argumentos utilizados que también coincidirán con los de la persuasión.

e. Existirá, necesariamente, la simulación, pero no en cambio la mentira, la cual podrá darse o no.

Para Carmen Herrero, el gran instrumento de la persuasión es el lenguaje; "poner nombre a las cosas no es solo una forma de ordenarlas y clasificarlas, sino también de dominarlas" (Herrero, 1996). Y es también el instrumento de la manipulación, entendida como tratamiento o acción que persigue conseguir unos fines ajenos al grupo que pretende manipular y desde luego al margen de la libertad de los individuos que componen este grupo. Herrero también dice que:

[...] La manipulación se diferencia de la persuasión, básicamente, por la existencia de dos niveles de intencionalidad, uno de los cuales no es conocido por el receptor al ser ocultado intencionadamente por el emisor. Es en el nivel oculto, ambiguo, no conocido, en el que se produce la manipulación. Los recursos de la manipulación son variados y van desde la ocultación de información o su deformación, a la mentira y la propaganda (Herrero, 1996). 


\section{Elementos básicos de la persuasión}

Los estudios actuales sobre la persuasión dan una importancia crucial a la fuente de la que parte la acción persuasiva. La fuente debe ser creíble para que el mensaje tenga efecto. Un mensaje es legítimo si quien emite el mensaje está socialmente legitimado para hacerlo, es decir, tiene autoridad moral o institucional. Para saber si un mensaje es legítimo se puede formular la pregunta: ¿Tiene esta persona autoridad para decir lo que dice? Si la respuesta es afirmativa, el mensaje es legítimo.

Un mensaje es competente si el mensaje es emitido de tal manera que el perceptor se ve obligado a procesarlo y a tomarlo en cuenta. La pregunta para saber si un mensaje es competente es: ¿Por su formato, obliga a ser procesado por el perceptor? Entre tanto, un mensaje es persuasivo si el mensaje moviliza emociones o cogniciones capaces de transformar una actitud.

Muchas veces un mensaje es persuasivo, pero poco competente. Por ejemplo, podemos haber visto veinte veces un anuncio de televisión sin comprender y atender al mensaje (baja competencia), pero si una vez, por casualidad lo hacemos, quedamos fascinados o hipnotizados, y procedemos a la compra del producto. El caso contrario, sería mensaje competente, pero no persuasivo. Una notificación de la Administración Pública donde vivimos, informándonos sobre el pago de una nueva tasa municipal, puede ser poco persuasiva (no nos convencen las razones del nuevo impuesto), pero seguramente analizaremos de manera concienzuda los pros y los contras de pagarla.

Entre tanto, un mensaje es apropiado si por su formato, por quien emite el mensaje, canal escogido y otras características, puede obtener los resultados trazados. Este concepto es muy global, pues se refiere a si en la vida real el mensaje ha logrado o no su propósito. La pregunta clave para saber si un mensaje es apropiado sería: ¿es o fue eficaz para cambiar conductas? Como es lógico, tanto más será un mensaje apropiado, cuanto más legítimo, competente y persuasivo.

\section{Procesos humanos: emociones y comunicación}

Para comprender la forma en que el ser humano interactúa con sus pares, es necesario entender el papel que juegan las emociones en las relaciones interpersonales dentro de las diferentes culturas y modos de entendimiento humano.

El psicólogo, por ejemplo, admite que el hombre tiene emociones porque la experiencia se lo enseña; así, la emoción es un accidente que no significa nada porque la estudia como un hecho, aislándolo de todo lo demás. La emoción significa a su manera el todo de la conciencia, y en el plano existencial, la realidad humana.

En la psicología, las emociones son estados centrales inducidos por determinados estímulos, que se traducen en modificaciones de una gran variedad de conductas. No es posible argumentar las emociones desde un único enfoque, ya que están conectadas con las siguientes teorías: la filosofía, que se interesa esencialmente por los aspectos subjetivos 
de las emociones, con independencia de su soporte orgánico (crea teorías). La biología expresa que la emoción solo es accesible, a través de las modificaciones objetivas que la acompañan; se interesa por los cambios conductuales y fisiológicos (observa reacciones). Para la psicología, las emociones son estados centrales inducidos por determinados estímulos, que se traducen en modificaciones en toda una variedad de conductas.

Aun así, la teoría psicológica es la que resume la esencia de las anteriores, es decir, la filosófica puede observarse en todas las teorías planteadas por la psicología; la biológica se puede distinguir en las diferentes conductas y reacciones fisiológicas, en este caso, ante las emociones; por esto es posible concluir que la psicológica es la más completa porque no solo se queda con crear teorías y observar reacciones, sino que se esfuerza por estudiar el porqué de esas reacciones, los estados cognitivos subjetivos y conductas expresivas para así poder argumentar, explicar y entender las diferentes actitudes que presentan los humanos ante las emociones. Ya que estas no se presentan de igual manera en todos los casos, muchas veces son más notorias que otras y varían respecto a la situación, el ambiente en el que la persona se encuentra o las experiencias que esta ha vivido.

Durante mucho tiempo, las emociones han sido consideradas poco importantes y siempre se le ha dado más relevancia a lo competente con la parte racional del ser humano. Pero las emociones, al ser estados afectivos, indican estados internos personales, motivaciones, deseos, necesidades e incluso objetivos. De todas formas, es difícil saber a partir de la emoción cuál será la conducta futura del individuo, aunque es posible intuirla. Tan pronto como el ser humano cuenta con unos meses de vida, adquiere emociones básicas como el miedo, el enfado o la alegría. Algunos animales comparten esas emociones tan básicas, que en las personas se van haciendo más complejas gracias al lenguaje debido a que tiene la habilidad para hacer uso de símbolos, signos y significados.

Cada individuo experimenta una emoción de forma particular, dependiendo de sus experiencias anteriores, aprendizaje y carácter, y de la situación concreta. Algunos de las reacciones fisiológicas y comportamientos mentales que desencadenan las emociones son innatos, mientras que otros pueden adquirirse. Asimismo, si se considera objetivamente al individuo como un sistema de conductas, y si la derivación se hace automáticamente, el fracaso no es nada, no existe, simplemente sustituye una conducta. Para que la emoción tenga significación, la conciencia ha de intervenir y conferirle esta significación aprehendiendo la emoción como un fracaso con respecto a una conducta superior. La emoción no es simplemente interpretada, no es un comportamiento puro, es el comportamiento de un cuerpo que se halla en un determinado estado.

De tal forma que las emociones son inherentes a la existencia humana y tienen un valor heurístico (capacidad de un sistema para realizar de forma inmediata innovaciones positivas para sus fines) en la explicación de las subjetividades e intersubjetividades. Las emociones en clave interdisciplinaria son mucho más que signo y síntoma de la salud mental, de la salud corporal; tienen que ver también con la experiencia del conocimiento, la experiencia social y finalmente la de ser y estar en el mundo de la vida cotidiana. 
Cada una de las emociones puede entenderse como una combinación específica de las dimensiones que se han mencionado. Tendiendo únicamente a estas no puede establecerse una clasificación exhaustiva y excluyente de todas las reacciones afectivas, puesto que emociones como la ira o el odio pueden ser desagradables e intensas, y no se trata del mismo tipo de emoción.

Del mismo modo, es difícil lograr una clasificación exhaustiva de todas las emociones posibles con base en dimensiones independientes. No obstante, la dimensión agradodesagrado sería exclusiva y característica de las emociones, de forma que todas las reacciones afectivas se comprometerían en dicha dimensión en alguna medida. Esta dimensión alguedónica ${ }^{5}$ de placer-displacer sería la característica definitoria de la emoción respecto a cualquier otro proceso psicológico. De forma similar, Oatley (1992) señala que lo realmente definitorio y diferenciador de las emociones es la disposición para la acción y la "cualidad fenomenológica". Así, una emoción podría definirse como una experiencia afectiva en cierta medida agradable o desagradable, que supone una cualidad fenomenológica característica y que compromete tres sistemas de respuesta: cognitivo-subjetivo, conductual-expresivo y fisiológico-adaptativo.

De otro lado, el componente conductual o expresivo de la emoción comprende un conjunto de conductas externas como expresiones faciales, movimientos corporales, conducta de aproximación-evitación, conducta verbal, entonación de la voz, intensidad, sonidos, entre otros. Así, por ejemplo, una persona con la boca abierta, las cejas alzadas y los ojos bien abiertos, al mismo tiempo que emite una exclamación, por ejemplo, ioh!, seguramente será calificado, sin grandes dificultades, su estado emocional, como de sorpresa.

Este componente de la emoción está muy influido por factores socioculturales y educativos que pueden modular la expresión emocional. De esta manera, la expresión emocional varía a lo largo del desarrollo ontogenético de la persona, y son los adultos los que ejercen un control emocional más grande en comparación con los niños. Por otra parte, las reglas sociales modulan la expresión emocional porque facilitan o inhiben la manifestación, de acuerdo con el contexto en el cual tiene lugar la experiencia emocional.

El componente cognitivo-experiencial de la emoción, como su nombre indica, incluye dos aspectos fundamentales de la emoción: el experiencial y el cognitivo. El componente experiencial está relacionado con la vivencia afectiva, con el hecho de sentir y de experimentar propiamente la emoción. Hace referencia al tono hedónico de la experiencia emocional, es decir, a los estados subjetivos calificados, por el sujeto, como agradables o desagradables, positivos o negativos que experimenta cuando es objeto de una emoción.

5 La afectividad se caracteriza, fundamentalmente, por ser una experiencia ALGUEDÓNICA, esto es, una experiencia de dolor o placer, de agrado o desagrado. Como acabamos de decir, múltiples circunstancias pueden desencadenar estas vivencias de placer o displacer. Los psicólogos han estudiado este complejo mundo de la afectividad y han dado múltiples teorías para explicar su origen. (Díaz Pedroch, 2000). Tomado de: http://montsepedroche.files.wordpress.com/2010/04/motivacionyafectividad.pdf 
El componente cognitivo se relaciona con el reconocimiento consciente que se hace del estado emocional, es decir, con la "etiqueta" que se le pone para identificarlos, por ejemplo decir: "soy feliz", "tengo miedo" o "me siento culpable". "Casi todo el mundo piensa que sabe qué es una emoción hasta que intenta definirla. En ese momento prácticamente nadie afirma poder entenderla" (Wenger, Jones y Jones, 1962).

\section{¿Qué son las emociones?}

En la teoría de las emociones, resulta pertinente y, además, necesario, establecer el vínculo que aquellas tienen con la condición humana. De acuerdo con el trabajo de autores que desde la psicología abordan este concepto, las emociones se constituyen en factores determinantes de la conducta humana y son básicas en la forma de los primeros elementos constitutivos de las simbologías, propias de nuestros actos comunicativos.

Las emociones están presentes en la vida de todas las personas, prácticamente en todo lo que emprenden, por ejemplo, estar con un amigo por un sentimiento de gusto al compartir con él, visitar a los abuelos por el afecto que se les tiene, ir el fin de semana a la playa con ánimo de pasarlo bien. Enfado cuando no nos salen bien las cosas y alegría y satisfacción cuando se logra el éxito en las metas propuestas. Temor a volar en avión o a ir a la consulta del dentista. Aflicción y dolor cuando muere un familiar, o alegría cuando la persona por la que se siente atracción corresponde a dicha emoción. Estas y otras situaciones de la vida cotidiana ponen de manifiesto la influencia que las emociones ejercen en las vidas de los seres humanos. Es posible afirmar que las emociones son inherentes a la propia condición humana y que, en gran medida, determinan su existencia (Wenger, Jones y Jones, 1962).

No obstante, y a pesar de su presencia continuada a lo largo de la vida, resulta muy difícil plantear una definición precisa de un fenómeno tan complejo como son las emociones. De hecho las definiciones han dependido de la posición teórica de los investigadores que se han dedicado a su estudio. De allí que, por ejemplo, desde una perspectiva biológica, los neurocientíficos hayan subrayado la importancia de los mecanismos cerebrales, hormonales como los neurotransmisores implicados en la emoción, sin tener tanto en cuenta el componente subjetivo experiencial. O bien, que desde una perspectiva cognitiva se haya enfatizado en la importancia de los procesos cognitivos (evaluación, pensamiento) y se hayan dejado de lado los aspectos fisiológicos y conductuales, mientras que, por ejemplo, los investigadores que se han centrado en los aspectos expresivos de la emoción, en particular las expresiones faciales, destaquen los aspectos comunicativos de estas, y dejen en un segundo plano otros aspectos (Wenger, Jones y Jones, 1962).

\subsection{Conceptos relacionados con las emociones}

Cuando se estudian las emociones se suelen proponer otros conceptos cuyos significados, por su proximidad semántica, pueden llevar a confusiones. Es el caso de las ideas de afecto, estado de ánimo, temperamento y sentimiento, las cuales se definen a continuación.

Afecto es el término que se utiliza para describir el tono hedónico o valencia de un estado emocional, es decir, su cualidad positiva - agradable- o negativa - desagradable-y su intensidad, que puede ser alta o baja. En este sentido, el afecto está relacionado con 
la preferencia, con el valor que tienen para el sujeto las diferentes situaciones a la cuales se enfrenta.

Los estados de ánimo, a diferencia de las emociones, no tienen especificidad, tienen carácter global y no tienen un objeto específico. En cambio, las emociones son intencionales, se dirigen hacia algún objeto o hecho, que puede ser externo o interno, que las provoca. Es decir, son reacciones específicas a acontecimientos particulares. Los estados de ánimo suelen durar más tiempo que las emociones y ser menos intensos; están siempre en la vida y proporcionan el fondo afectivo, el "color emocional" a todas las acciones.

El temperamento estaría formado por el conjunto de rasgos o diferencias individuales, características, estables durante largos períodos de tiempo, en relación con las maneras en las que las personas experimentan y expresan sus emociones. En otras palabras, sería la tendencia a responder emocionalmente de una manera particular.

El concepto de sentimiento se utiliza para explicar las propensiones o inclinaciones que tienen las personas para responder de manera emocional, bien delante de objetos particulares o delante de cierto tipo de circunstancias. Así, por ejemplo, expresiones como "odio a los gatos" o "me gusta el fútbol" serían representativas de este fenómeno emocional; de la misma manera lo serían las actitudes xenófobas hacia los inmigrantes. En este sentido, el amor o el odio serían entendidos más como sentimientos que como emociones. Las dos palabras se refieren más a maneras de ver y tratar un objeto, que a una respuesta momentánea. De todas formas, los sentimientos y las emociones estarían estrechamente relacionados: los sentimientos son las bases para las emociones cuando sucede una cosa que implica un objeto.

\section{A modo de cierre}

Tal como se dijo al inicio de este artículo, la investigación se encuentra en su fase inicial y exploratoria. Si bien, los investigadores somos conscientes de que el trabajo de campo será determinante para establecer hallazgos del proceso investigativo, sin temor a equivocarnos y luego de realizar el rastreo teórico del tema, compartimos con nuestros lectores algunos conceptos puntuales de este acercamiento a teorías que, sin duda alguna, nos conducirán a llevar a feliz término el propósito que nos hemos trazado desde las diferentes univesidades participantes en el proyecto y pertenecientes a cuatro países de América.

Los siguientes son algunos hallazgos parciales, mas no concluyentes, de dicho acercamiento a teorías:

- Actualmente, la comunicación se ha convertido en una herramienta estratégica dentro de cualquier organización que quiera posicionarse en el mercado. Esto no quiere decir que la comunicación sea la clave del éxito, pero sí que forma parte de este, y de hecho a través de ella se va a acercar al mercado la imagen que pretenda mostrar determinada empresa; esto la posicionará de forma más competitiva. Indudablemente, 
la realidad demuestra que posicionar una empresa o producto requiere de un estudio previo del mercado, para conocer qué es lo que desea el público, seguido del lanzamiento del producto o servicio que mejor satisfaga sus necesidades, a través de los canales de distribución más rentables y, por último, su comercialización. Hasta aquí, nada que no hagan todas las organizaciones o instituciones. Por lo tanto, lo que brinda la posibilidad de diferenciarse del resto va a ser la comunicación, entendida en su sentido más global, ya que va aportar un valor agregado, permitiendo crear en el consumidor la necesidad de adquirir un producto y hacer que el cliente elija ese frente al de la competencia.

- En una sociedad en la que todo comunica, no gestionar de forma adecuada la comunicación y con ella las relaciones públicas de la empresa puede significar un riesgo para la misma. El contexto de la comunicación de hoy es otro, principalmente surgido de la evolución del mercado y de las nuevas tecnologías, que ha llevado a crear un concepto de comunicación más participativo, interpersonal, global y activo. Así la comunicación y las relaciones públicas, entendidas desde su acción persuasiva, son una de las principales herramientas que tiene una organización para alcanzar los resultados que espera, y se hace fundamental poder integrarlas a la estrategia empresarial.

- Las relaciones públicas constituyen la función administrativa que evalúa las actitudes del público, identifica las políticas y los procedimientos de una organización, y ejecuta programas de acción y comunicación, para ganar la comprensión y la aceptación del público, con el fin de que una buena imagen de la empresa interfiera a través de los sentidos en sus respectivos públicos para así lograr la obtención de mejores posibilidades para competir y obtener mejores resultados económicos.

- La adquisición de las competencias emocionales adecuadas se manifiesta en la capacidad para expresar, controlar y regular la emoción. La expresión emocional ajustada es aquella que coordina los distintos canales de comunicación emocional (verbal, conductual, facial y vocal) para trasmitir una emoción dada. La regulación emocional consiste en poner en práctica estrategias sobre comportamiento, cognitivas, atencionales y fisiológicas para eliminar, mantener o cambiar la experiencia emocional, para encajar la emoción al momento y contexto adecuados para expresar dicha emoción. Estos tres aspectos de la comunicación emocional deben funcionar armónicamente, para que la emoción cumpla con su papel.

- Si bien las emociones son inherentes a la conducta humana, es importante señalar que estas son constitutivas de y responsables de los procesos de simbología entre actores. Luego, determinar el papel que estas cumplen entre los diversos públicos de las organizaciones nos ayudará a una mejor comprensión de las interacciones y las simbologías que transcurren y discurren entre los diferentes integrantes de las organizaciones y de estas con sus diferentes grupos de interés o stakeholders. 


\section{Referencias bibliográficas}

Aguadero Fernández, F. (1993). Comunicación social integrada: Un reto para la organización. Barcelona: Consejo Superior de Comunicación y Relaciones Públicas de España.

Arceo Vacas, J. L. (1988). Fundamentos para la teoría y técnica de las relaciones públicas. Barcelona: Promociones y Publicaciones Universitarias.

Aristóteles. (1985). La retórica. Madrid: Centro de Estudios Constitucionales.

Berrío, J. (1983). Teoría social de la persuasión. Barcelona: Editorial Mitre.

Borrat, H. (1989). El periódico actor político. Barcelona: Editorial Gustavo Gili.

Borrell, F. (2000). Comunicar bien para dirigir mejor. Barcelona: Ed. Gestión 2000.

Borrell, F. (2001). Comunicar bien para dirigir mejor. Barcelona: Gestión 2000.

Costa, J. (1999). La comunicación en acción. Barcelona: Editorial Ciac Internacional-Paidós.

Costa, J. (2003). La imagen pública: una ingeniería social. Medellín: Asociación Iberoamericana de Comunicación Estratégica -AICE-

Cutlip, S. y Center, A. (2000). Relaciones públicas eficaces. Barcelona: Ediciones Gestión 2000.

Escarpit, R. (1983). Teoría de la información y práctica política. México: Fondo de Cultura Económica.

García Gordillo, M. del M. (2000). La manipulación en la construcción de la realidad internacional. Revista Razón y Palabra, número 17.

García Gordillo, M. del M. (2008). Asignaturas en red. Periodismo político internacional. Sevilla: Universidad de Sevilla. Secretariado de Publicaciones.

Gruning, J. (2000). Dirección de relaciones públicas. Barcelona: Ed. Gestión 2000.

Marston, J. E. (1963) Modern public relations. Edition, illustrated, reprint, revised. Publisher, McGraw-Hill.

Pizzolante, I. (2003). "El poder de la comunicación estratégica". Asociación Iberoamericana de Comunicación Estratégica. Colección Hermes, N. 3, 2003.

Rivadeneira Prada, R. (1984). La opinión pública. Análisis, estructura y métodos para su estudio. México D. F.: Editorial Tirillas.

Santamaría, L. (1990). El comentario periodístico. Los géneros persuasivos. Madrid: Ed. Paraninfo.

Scheinsohn, D. (2009). Comunicación estratégica. Buenos Aires: Ediciones Granica S. A.

Searle, J. R. (1997). La construcción de la realidad social. Barcelona: Paidós.

Soria, C. (1997). El laberinto informativo. Navarra: Editorial EUNSA.

Xifra, Triadú Jordi. (2010) Relaciones públicas, empresa y sociedad. Una aproximación ética. Barcelona: Editorial el Ciervo.

\section{Referencias de internet}

www.centrodocumentaciondown.com. ¿Qué son las emociones? Recuperado 02 de febrero de 2012. http://portal.iteso.mx/portal/page/portal/Dependencias/Rectoria/Dependencias/Direccion_General _ Academica/Dependencias/DESO/Programas _ academicos/MC/coloquio _ de _ proyectos/ PROTOCOLOS _ 2012/ProtocolodeinvestigacionCŪARENTA2012.pdf 
http://psicopsi.com/Cognicion-y-emocion. Cognición y emoción. Recuperado 26 de febrero de 2012. http://www.slideshare.net/JEMWONG/15 8209786. Wong, F. Emociones y sentimientos. Recuperado 03 de mayo de 2012.

http://www.redalyc.org/pdf/297/29720421003.pdf Xifra, Triadú Jordi. (2010) Las Relaciones Públicas: ¿Ciencia norteamericana? ¿Ciencia occidental? ¿Ciencia universal? núm. 7, 2007, pp. 29-44. Universidad Católica San Antonio de Murcia, España. 